\title{
Autoridade e política: a gestação do conceito de ditadura em Donoso Cortés e sua recepção por Schmitt
}

\section{Authority and politics; Dictatorship concept gestation accor- ding to Donoso Cortés and its receptivity by Schmitt}

\author{
Roberto Bueno ${ }^{1}$
}

\begin{abstract}
Resumo
O objeto deste artigo é analisar se os conceitos de autoridade e política forjados pelo conservadorismo contrarrevolucionário de Donoso Cortés no século XIX puderam contribuir para o desenvolvimento do conceito de ditadura no século XX com Schmitt. Foram realizadas aproximações conceituais específicas entre a ditadura, a concepção de autoridade fundamentalmente por intermédio de duas vias conectivas, a saber, a fundamentação teológica destes conceitos e, por outro lado, o recurso ao conservadorismo de maistreano objetivando a ampliação do conhecimento sobre a gramática conservadora nesta matéria. Este artigo problematiza a teoria da ditadura de Donoso com a especial preocupação de delinear alguns de seus pontos de partida estendendo algumas vias hermenêuticas que permitam ampliar a linha compreensiva do sentido que a violência e o político aportam na reflexão filosófico-política de Donoso Cortés em face da excepcionalidade. Voltar a estes problemas fundamentais da filosofia política contribui de modo relevante para o desenho de novos quadros interpretativos da realidade política. Fazê-lo desde as linhas de Donoso Cortés apresenta a vantagem adicional de apresentar autor apenas parcialmente conhecido no Brasil, mas que, paralelamente, é fonte de seu conservadorismo.
\end{abstract}

Palavras-chave: Donoso Cortés; Ditadura; Autoridade; Teologia.

\section{Abstract}

The aim of this article is to analyze if the concepts of authority and politics forged by the Donoso Corté's counterrevolutionary conservatism in the nineteenth century could contribute to the development of the concept of dictatorship in the twentieth century with Schmitt. Specific conceptual approaches were made between the dictatorship, the concept of authority fundamentally

Professor Adjunto I da Faculdade de Direito da Universidade Federal de Uberlândia (UFU). Pós-doutorando em Direito (USP/SP). E-mail: rbueno@hotmail. com

Ano $13 \cdot$ n. $1 \cdot$ jan./jun. $2013-61$ 
through two connectives pathways, namely, the theological grounding of these concepts and, on the other hand, the resource of Maistrean conservatism aiming to increase the knowledge about the conservative grammar in this matter. This article problematizes the Donoso's theory of dictatorship with a special care to outline some of its starting point understanding some of the hermeneutic options which allowed to increase the understanding line of the sense in which the violence and the political contributes to the political philosophy reflections of Donoso Cortés, in face of the excepcionality. Going back to these fundamental problems of the political philosophy contributes in a relevant way to the design of a new interpretative frame of political reality. Doing it since the lines of Donoso Cortés presents the additional advantage of presenting an author only partially known in Brazil, but at the same time, a source its conservatism.

Key words: Donoso Cortés; Dictatorship; Authority; Theology.

\section{Introdução}

Assumimos que o debate sobre o conceito de autoridade é um dos mais relevantes na filosofia política e, logo, retornar à sua análise é trabalho sempre marcado pela atualidade. A contribuição destas linhas parte da perspectiva assumida pela tradição política conservadora espanhola, católica e contrarrevolucionária, presente tanto nos textos de Donoso Cortés quanto nas linhas de De Maistre, e tão intensamente presente no espírito político contrarrevolucionário atento aos fenômenos de 1848 (ver SÁNCHEZ GARCÍA, 2008).

Donoso reduz a aproximação ao conceito de autoridade segundo uma interpretação teológica cuja amplitude lhe permite, passo seguinte, consolidar as bases do seu conceito de ditadura. Para a realização da investigação proposta acerca das conexões conceituais entre a ditadura e a autoridade é precisamente esta abordagem realizada por meio de uma fundamentação teológica da qual lançaremos mão. Para redimensionar o campo epistemológico-conceitual desde o qual opera Donoso é que recorreremos à análise conjunta dos trabalhos de De Maistre, importante fonte do extremenho.

A realização deste trabalho dialoga necessariamente com alguns dos textos centrais de Donoso, respeitados os necessários 62 - Universidade Católica de Pernambuco 
recortes. O principal deles é o seu famoso Discurso sobre la dictadura $^{2}$ (DSD) pronunciado no Congresso espanhol a 4 de janeiro de 1849 (ver DONOSO CORTÉS, 1954). Indispensável referencial teórico para avançar na compreensão do objeto em questão é o conjunto de outros três textos de Donoso. O nosso foco neste texto é retomar um trabalho menos conhecido entre nós do autor, a saber, Ley de Estados Excepcionales (ver DONOSO CORTÉS, 1946a), mas também, em menor medida, La civilización de España (ver DONOSO CORTÉS, 1946b) e as Lecciones de Derecho Político (ver DONOSO CORTÉS, 1946c). Nesses textos, o autor oferece importantes subsídios não apenas para a elaboração de sua concepção de ditadura como, e talvez decisivamente, sobre os limites conceituais desde os quais pensa o político.

Metodologicamente, optamos por construir este brevíssimo texto realizando uma divisão interna em duas grandes partes. Na primeira delas, visamos a cumprir, ao fundo, a tarefa de contextualizar a crise europeia da primeira metade do século XIX e inserir neste período a sua LEE, que, precisamente, visava a constituir-se em uma proposta concreta aos problemas históricos.

Na terceira seção, ocupamo-nos da argumentação em prol da ditadura segundo a qual esta se faz necessária por força da imprevisibilidade fática e inabordabilidade jurídica das situações de excepcionalidade. Este trabalho analítico foi realizado desde o prisma teológico-político. Esta seção ocupa-se da análise do argumento de que a ditadura é uma resposta necessária em face da imprevisibilidade, fática, e jurídica, das circunstâncias que compõem a situação excepcional à qual se aplica a ditadura. Esta seção abordará a resposta ditatorial ao excepcional pela via do teológico.

Daqui em adiante eventualmente adotaremos as abreviaturas para as seguintes obras mais citadas de Donoso Cortés neste texto: (a) Discurso sobre la dictadura (DSD); (b) Ley de Estados Excepcionales (LEE); (c) La civilización de España (LCE); (d) Lecciones de Derecho Político (LDP); (e) Discurso sobre la situación General de Europa (DSSE). 


\section{A radicalização da crise: 0 contexto europeu da ditadura e o projeto de resposta jurídica (ley de los estados excep- cionales)}

O objeto desta primeira seção é a contextualização histórica e sua repercussão teórica especificamente no momento em que Donoso opera em seu segundo e derradeiro período conservador que esteve coordenado com os últimos anos de sua vida. O traçado geral deste período europeu de crises permitirá melhor compreender quais são os referenciais políticos com os quais dialoga o nosso autor e, sobretudo, quais são as respostas que o seu trabalho é capaz de oferecer, e sob quais argumentos o realiza em circunstâncias de crise como a daquele momento histórico de meados do século XIX.

No ano de 1849, Donoso Cortés chamou a atenção por meio da alta densidade de sua crítica não apenas contra o parlamentarismo mas também contra o caráter e o modus operandi dos parlamentares, ${ }^{3}$ conjunto de elementos que logo iriam revelar-se decisivos para a consolidação de sua posição em face das crises políticas de seu tempo. Embora seu texto indicasse não subsistirem dúvidas sobre a preferência humana sobre a vida em liberdade, na prática, para ele, o fato é que ela já não era uma realidade na Europa, muito embora eurocentricamente admitisse que a Grécia e Roma tivessem sido o berço da liberdade na história humana

Há em Donoso Cortés, como houve em De Maistre, uma intensa crítica às instituições parlamentares ou republicanas este é um lugar em que a soberania não é vista como tão palpável como nas monarquias (cf. DE MAISTRE, 1990, p. 114). Também intensas foram as críticas de que as estruturas políticas possuem como base comum a representação política, posto que a própria ideia de representação popular é algo nunca visto ( $c f$. DE MAISTRE, 1990, p. 43). Tanto Donoso quanto De Maistre também críticas intensamente a fragmentação do poder, absolutamente atentatórios assim como a representação, ao que ambos os autores consideram o núcleo duro do conceito de soberania (ver DE MAISTRE, 1990, p. 45). Assim, por exemplo, diz o savoiano que "No puede existir una gran nación libre bajo un gobierno republicano. La cosa es tan clara por sí misma, que la teoría podría prescindir de la experiencia [...]”. (DE MAISTRE, 1990, p. 27; 41). 
(cf. DONOSO CORTÉS, 1946b, p. 937), em ampla desconsideração à história humana universal. Ao reconhecer que a liberdade havia sido perdida, passo seguinte, desenhava um obscuro quadro político de um período que Schmitt denominou de primeira guerra civil europeia (cf. SCHMITT, 1995, p. 135-146). ${ }^{4}$ Essa foi uma das estratégias de Donoso para, logo, apostar em opções políticas tão intensas e radicais quanto irreversível o mal ao qual declaradamente visava a atacar e, por fim, estancar.

A razão para esta decadência geral da Europa era identificada por Donoso nas ações debilitadoras empreendidas pelos governos constitucionais, ou seja, que com o suceder de equívocos políticos eles se tinham transformado em nada mais do que meros esqueletos sem vida ( $c f$. DONOSO CORTÉS, 1904b, p. 131), muito distantes, portanto, de tudo quanto um dia haviam representado em matéria política e, assim, estavam a colocar os trilhos de uma análise que seria retomada por Schmitt em sua Die geistesgeschichtliche des heutigen Parlamentarismus (ver SCHMITT, 2010). ${ }^{5}$ Este evento constitucional somava-se à influência que sofria do anticlericalismo liberal e seu ataque à Igreja Católica. Este é o aspecto principal do cenário que foi desenhado por Donoso e considerado como uma paisagem caótica que reclamava intervenção. A partir desta descrição histórica de fundo, Donoso opera e extrai argumentos para justificar e consolidar a sua opção política pela ditadura.

$4 \quad$ Schmitt chama a atenção para a reação de Donoso neste contexto perigoso: tratava de fazer ao poderoso ainda mais poderoso (cf. SCHMITT, 1995, p. 135-146). Mas, e o que é ainda mais relevante, "Donoso traza aquí la imagen de un leviatán que todo lo devora, al que la técnica provee de mil manos y oídos, y contra cuyo poder, centuplicados por la técnica, todos los intentos de control o contrapeso son vanos o absurdos". (SCHMITT, 1995, p. 139).

Um dos momentos em que claramente Schmitt evidencia a completa decadência do Parlamento, ao chamar a atenção para que ele deixa de exercer as suas funções precípuas e transforma-se em uma formalidade vazia: "Sind Öffentlichkeit und Diskussion in der tatsächlichen Wirklichkeit des parlamentarischen Betriebes zu einer leeren und nichtigen Formalität geworden, so hat auch das Parlament, wie es sich im 19. Jahrhundert entwickelt hat, seine bisherige Grundlage und seinen Sinn verloren". (SCHMITT, 2010, p. 63).

Ano $13 \cdot$ n. $1 \cdot$ jan./jun. $2013-65$ 
Um texto secundário sobre a ditadura, mas esclarecedor em certos pontos, é o Discurso sobre la situación General de Europa (ver DONOSO CORTÉS, 1904a) que Donoso pronuncia em 20 de janeiro de 1850, logo na sequência de seu retorno de Berlin. Embora não faça expressa referência ao tema, há nele uma conexão temática interna com a questão da ditadura. No texto, o autor compromete-se com uma redação elucidativa a respeito de sua interpretação da história bem como das vicissitudes que o golpeiam e, momento seguinte, destaca as sérias repercussões políticas disto derivadas. Ao sofisticar a descrição do quadro histórico com análises filosóficas e teológicas, o autor termina por agravar as circunstâncias históricas com as quais trabalha e assim começa a colocar as bases para a sua alternativa política radical. Neste texto, Donoso descreve a turbulência europeia como um incessante processo anticatólico que se consolidara a partir dos esforços do fenômeno revolucionário francês, mas sem esquecer os movimentos antipapais dos reformistas. ${ }^{6}$

Ambos os movimentos granjearam adeptos, sendo notável a rapidez da penetração do racionalismo alimentado pela filosofia da Ilustração, que logo emprestaria apoio às opções políticas que triunfaram transitoriamente no primeiro quarto do século XIX na Europa e na Espanha, sendo neste último Estado bastante claro o movimento jurídico-político representado pela Constituição de Cádiz que, sob proteção britânica, fez ascender ao trono espanhol José I e conduzir ao exílio Fernando VII. Péssimo quadro para a construção de um marco jurídico-político estável, ao menos aos olhos de alguém que, como Donoso, apostava na tradição e no catolicismo e não no racionalismo, no ateísmo ou no laicismo.

Naquela quadra da história, a análise de Donoso Cortés tinha em perspectiva parcialmente o cenário político e insti-

\footnotetext{
6 A posição anticentralizadora de Lutero relativamente ao poder papal é apresentada em diversos momentos, e com ela, desde logo, Donoso Cortés não poderia convergir. Sobre a posição de Lutero ver LUTERO, (1998). No mesmo sentido ver DE BONI, (2000) e também HOPFL, (2005). 
tucional da Inglaterra e da França. No caso dessa última, o autor destacava que a revolução de julho francesa fizera estremecer os alicerces de toda a sociedade, atribuindo-lhe os mais diversos e terríveis crimes, inversamente ao conjunto das ações e resultados obtidos pelos bons defensores da religião e da monarquia ( $c f$. DE MAISTRE, 1990, p. 108). O novo poder que então emergia destituiria o rei (absoluto) e, passo seguinte, entronizaria a lei em seu papel supremo, sendo que a ela não poderiam ser opostos poderes ou medidas. $\mathrm{O}$ império da lei e o elogio da legalidade obrigavam que a cultura do absolutismo experimentasse o seu ocaso e, então, as medidas excepcionais passavam a ser alternativas legalmente proscritas, visceralmente repugnantes a um sistema calçado na previsão do legislador consignada em lei material que, desse modo, armava o roteiro da segurança, certeza e previsibilidade jurídica dos regimes liberais.

A resposta política e a jurídica de Donoso Cortés às vicissitudes da época encontram-se parcialmente exposta em seu LEE (ver DONOSO CORTÉS, 1946a), publicado no ano de 1839, na Revista de Madrid. O que Donoso declara objetivamente é estar à procura de realizar aportação para a construção de uma legislação que compatibilize a liberdade dos indivíduos e a fortaleza do governo quando estivessem postas as circunstâncias nebulosas, complexas e difíceis (ver DONOSO CORTÉS, 1946a, p. 627). ${ }^{7}$ O marquês de Valdegamas reconhece que, para os tempos difíceis, o trabalho do legislador não disporia de respostas eficazes e é por esse motivo que o legislador não pode ligar as suas ações deliberativas a algum sistema jurídico específico. Esse reconhecimento de insuficiência é orientado pela ideia de que "[...] cuando los acontecimientos reclamen su acción, su acción ha de ser tan rápida como las circunstancias exijan [...]" (DONOSO CORTÉS,

Residualmente serão analisados e contrapostos outros textos donosianos como instrumento de análise dos temas propostos centralmente nestes dois mencionados trabalhos. 
1946a, p. 628) ${ }^{8}$ e que, por certo, tal específica previsibilidade não é característica do campo de amplitude das normas jurídicas.

Neste contexto de conturbações, Spektorowski destaca a ideia de que a preferência (e fascínio) de Donoso Cortés pelo conceito de autoridade, assim como também seria percebido por De Maistre, que opera em detrimento da noção de deliberação no âmbito do político. Esse aspecto justificaria a posição de alguns comentaristas primariamente, embora não definitivamente, no sentido de perfilar a ambos os filósofos conservadores como pensadores originários da ideologia fascista ( $c f$. SPEKTOROWSKI, 2002, p. 295) à medida que, paralelamente à atividade de solapar a representatividade, põe em destaque e petrifica em seu sistema teórico o conceito de autoridade.

Ainda quando não seja expresso e minucioso sobre a matéria quanto poderia ser o texto de um especialista em teoria do direito, Donoso avança argumentos e reconhece que a legislação positiva possui sérias limitações quanto à antecipação de eventos futuros. Donoso compreende que esta ordem de expressos limites implica necessárias lacunas que não podem ser preenchidas ainda pelos mais previdentes legisladores. Para o autor, é impensável a elaboração de uma legislação específica a respeito dos momentos de exceção, e o que é mais, tecnicamente inviável. Tal é um objetivo de impossível realização, pois "[...] ¿cómo sujetar al inflexible yugo de reglas determinadas y fijas un Estado en que los vínculos sociales se disuelven, en que la autoridad pierde su vigor y sus mandatos el prestigio?" (DONOSO CORTÉS, 1946a, p. 632). Donoso não encontra meios para responder positivamente ao dilema entre a instabilidade profunda, cujas circunstâncias concretas não são perfeitamente mensuráveis e, por outro lado, qual a intensidade das medidas necessárias de que deva dispor uma autoridade para suplantar tal excepcionalidade.

Este tema será algo mais detalhadamente analisado na terceira seção deste trabalho. 68 - Universidade Católica de Pernambuco 
Malgrado a impossibilidade desse tipo de legislação, o seu conteúdo bloqueado, todavia, segue a demandar preocupação empírica específica, pois permanece como um problema o fato concreto das rebeliões contra as autoridades. Essa é uma circunstância que é atualizada historicamente para a qual alguma resposta o Estado necessariamente deverá apresentar. Claro está para o autor que, em face da oposição do conjunto de rebeldes contra a mansidão da lei que, então, o momento legitimaria aos seus defensores para transcender os limites da lei, vencê-los com vistas a proceder à sua defesa, e tão intensamente quanto a realização prática do objetivo requeira ( $c f$. DONOSO CORTÉS, 1946a, p. 639). Assim, quando da radicalização da situação de enfrentamento, e quando já estivessem desafiadas à morte as forças de estabilização do status quo, quando as perspectivas de resistência ou obstáculos por parte do poder instituído fossem bastante reduzidas, então, em face da percepção da ruína do Estado dada a ausência de força política forte o suficiente, haveria o poder de recorrer a forças extraordinárias capazes de contrapor-se à excepcionalidade histórica, aptas a reverter a situação ao exercer o poder em toda a sua intensa e radical medida (ver DONOSO CORTÉS, 1946a, p. 628).

A expectativa de ausência de resistência por parte do opositor é mesmo uma característica do poder absoluto ( $c f$. DONOSO CORTÉS, 1933b, p. 155). Donoso Cortés admite que "El derecho común es la regla ordinaria de los hombres en tiempos bonancibles" (DONOSO CORTÉS, 1946a, p. 633), e com isso, certamente, podemos concordar, mas não com os seus desdobramentos. Contudo, o autor põe em destaque que recursos amplíssimos são requisitados para o enfrentamento dos tempos de exceção e isso encontra clara sinalização ao dizer que "El legislador que, en tiempos de disturbios y trastornos, aspira a gobernar con las leyes comunes, es imbécil [...]" (DONOSO CORTÉS, 1946a, p. 633). Opor-se ao núcleo duro da proposta donosiana, posteriormente retomada por Schmitt, não equivale a sugerir que os tempos excepcionais não façam com que a organização sociopolítica e jurídica não responda de forma diferenciada do que o 
faz em tempos ordinários. Contudo, a radicalidade do remédio donosiano põe a perder precisamente aquilo que, segundo sugere, propõe-se tão decididamente salvar, a saber, o regime de normalidade. Difícil dar crédito a Donoso, posto que introduz um regime de exacerbação de poderes e de excepcional violência, e isso sem a possibilidade de que possam ser mantidas quaisquer garantias contra a sua perpetuação.

Mesmo considerando a advertência de Donoso de que mesmo em tempos de distúrbios e transtornos o governante deve fazer uso e aplicar a legislação ( $c f$. DONOSO CORTÉS, 1946a, p. 633), o fato é que, dada a intensidade do poder que outorga ao soberano, e isso termina por tisnar definitivameinte a sua opção jurídico-política. A concessão de tão intenso poder leva a que esta estrutura reste demasiado pesada, blindada, invólucro invencível em face de (um improvável) retorno à normalidade. Em sentido próximo a este, observa González Casanova, em sua análise da ditadura franquista, que quase um século antes as referências de Donoso, Pacheco e Cánovas ao ditador soberano tiveram lugar no Decreto da Junta de Defesa Nacional rebelde de 29.6.1936. ${ }^{9}$

A possibilidade do normal é, portanto, absorvida pela indestrutível capa protetora do poder excepcional que veio a resolver o risco do caos, mas que ao resumir o político ao querer do soberano absoluto termina por implementá-lo definitivamente. A partir de seu conjunto de ideias, então, Donoso sente-se confortável para concluir que o direito excepcional é a regra comum em

\footnotetext{
Em virtude disto é que “[...] el general Franco asumirá todos los poderes del nuevo Estado. Las "leyes" por él dictadas en 1938 y 1939 le otorgaron "la suprema potestad de dictar normas jurídicas de carácter general" sobre "la estructura orgánica del Estado" y "el ordenamiento jurídico del país" (GONZÁLEZ CASANOVA, s/d). Mas o que é mesmo decisivo como prova histórica da tendência à permanência das ditaduras instauradas vem na sequência: "Tales atribuciones, según la Disposición Transitoria 1ª., II de la Ley Orgánica del Estado de 1967, "subsistirán y mantendrán su vigencia hasta que se produzcan las previsiones sucesorias" (GONZÁLEZ CASANOVA, s/d). Assim observa-se que uma vez armada a blindagem ao poder para que proceda ao exorcismo das forças do caos, em realidade, termina este por tornar-se a sua versão definitiva.
}

70 - Universidade Católica de Pernambuco 
tempos excepcionais ( $c f$. DONOSO CORTÉS, 1946a, p. 633), e que o direito ordinário o será para os tempos de estabilidade e bonança. Nesse sentido, o conceito de legalidade sofre uma brutal restrição, abandonando a sua posição de limitador de ações para ocupar a de conceito utilitário, cuja extensão é definida pelo poder soberano do momento.

O conceito de legalidade é deslocado de sua posição de limitador de ações do poder (lato sensu), e sem considerações de ordem teleológica ou finalística, mesmo quando isto suponha que algumas medidas para salvar a sociedade estejam sob juízo. A restritividade presente neste conceito de legalidade é substituída por um remédio político, a saber, pelo recurso à ditadura (ver DONOSO CORTÉS, 1904b). Sem a previsão de alternativas para suplantar a circunstância de excepcionalidade Donoso projeta como regra a manutenção das normas jurídicas invasivas dos direitos individuais e coletivos. Essa gama de restrições encontra-se à disposição do soberano, cujo poder se espraia ainda mais intensa e vorazmente à medida que é capaz de determinar a duração da excepcionalidade segundo seus exclusivos (e excludentes) critérios.

De modo conexo, em suas LCE, Donoso argumentava que o valor do catolicismo era precisamente o de apresentar singular capacidade de estabilizar o mundo. Virtude superior, ele o faria não pela ruptura política e violência e nem tampouco pela introdução de tábuas de direitos, mas, antes pelo contrário, pela prescrição de deveres aos indivíduos ( $c f$. DONOSO CORTÉS, 1946b, p. 940). Em face do supremo risco, a ditadura é brandida como alternativa temporal, à semelhança da força em estado bruto manifestada pelo poder transcendente. O poder temporal tem à sua disposição todo um voluptuoso e terrível aparato de força para o momento em que o soberano avaliar tornar-se necessária a "[...] reconcentración de toda la fuerza social en una sola mano, dispensadora entonces de la muerte o de la vida". (DONOSO CORTÉS, 1946a, p. 635).

Mas se o poder dispõe mesmo de tanta força, não necessariamente haverá de lançar mão dele. Nesse sentido, portanto, ao recordar a Cisneros, retomamos a ideia de que existem dois tipos 
de fazer política, e apenas um deles diz respeito ao exercício da política por meio da força, da luta intensa e apaixonada. Por outro lado, há uma concepção da política em que há uma busca pelo consenso e pelo acordo ( $c f$. CISNEROS, 2002, p. 625), em suma, que está mediada pelo diálogo. Em suma, trata-se de uma reação autoritária aos movimentos que, desde práticas revolucionárias, propugnavam a extensão dos direitos políticos, algo que, naquele contexto espanhol de meados do século XIX equivalia à defesa da democracia, do sufrágio universal e das transformações políticas e sociais ( $c f$. GÓMEZ ORFANEL, s/d, p. 1). ${ }^{10}$

Mas bem, o problema é que o detentor do poder não apenas se encontra nesta posição privilegiada para analisar e intervir no campo do político como resultado da confluência desses dois elementos, a intolerância pode reinar no cenário político. O triunfo da intolerância dá-se ao reconhecer o outro dissonante como $o$ adversário. Assumir o outro como adversário implica que a sua postura representa um risco para a unidade do bem e do virtuoso representada pelo poder dominante e pela ordem constituída. Nesse sentido, conforme reconhece Cisneros, "[...] el adversario, debe ser anulado y suprimido porque amenaza el futuro, hace peligrar la realización y la identidad del grupo de pertenencia" (CISNEROS, 2002, p. 632). Essa é uma tradição de pensamento do político que não pode manter-se de acordo com a defesa da democracia, que entre os seus pressupostos básicos encontra a participação, o compartilhamento de responsabilidades públicas e o respeito às dissidências políticas, tanto por intermédio do direito de expressão (imprensa) quanto pelo de reunião. Desse modo, o projeto político que assumir o outro dissidente como um ad-

10 A intolerância e as formas de governo autoritário não podem encontrar sólida guarida senão nesta primeira hipótese, e esta, certamente, foi a opção de Donoso e daqueles que lhe seguiram os passos, que apostam no sabre para instituir a paz a ferro e fogo, desconhecendo que o seu propósito somente pode ser alcançado pela aproximação dialógica e pactada, quando não literalmente consensuada.

72 - Universidade Católica de Pernambuco 
versário cujo combate não supõe o diálogo mas o enfrentamento violento à morte pertence a uma tradição fugidia aos mais caros princípios dos valores que orientam as democracias contemporâneas.

Para Donoso, contudo, o emprego dessa força justifica-se, pois todos aqueles que se preocupam com os direitos individuais não podem a ele sobrepor, tal como se fora um valor ainda mais alto, a saber, o da absoluta segurança do Estado (cf. DONOSO CORTÉS, 1946a, p. 639), senão que articular-se é a tarefa. Aqueles que defendem o Estado colocam-se em convicta posição de posse da verdade. A esse respeito menciona Cisneros que considera aos demais como "equivocados", e que, por conseguinte, podem encontrar-se em tal posição de oposição que "[...] merecen ser eliminados, ya que son "enemigos y traidores" del status quo y del orden imperante” (CISNEROS, 2002, p. 632). Esta é uma compreensão radical não apenas do que seja o papel do Estado mas, sobretudo, e muitíssimo mais perigoso de que o juízo de um só, o soberano ditador, haverá de encontrar os critérios mais acertados para definir quem sejam os inimigos e com quais meios enfrentá-los, até mesmo à morte.

Donoso não foge à realidade e, logo, chama a atenção para o fato de que perceberemos que "Las facultades discrecionales concedidas a la autoridad serán consideradas por algunos como atentatorias de aquellos preciosísimos derechos que no pueden abandonar sin deshonrarse los pueblos civilizados y libres" (DONOSO CORTÉS, 1946a, p. 639). E esta é mesmo a conclusão a qual pode alcançar-se, talvez a única, do rumo teórico apontado por ele. A sua posição, contudo, é bastante clara ao reconhecer estar intimamente convencido de que o valor superior a ser tutelado é o de eludir o grave risco da dissolução dos vínculos sociais, pois nesta condição todos os demais vínculos e direitos finalmente naufragam ( $c f$. DONOSO CORTÉS, 1946a, p. 639). $\mathrm{O}$ ataque essencial aos vínculos sociais deriva, precisamente, de uma percepção de que o outro está aposto e disposto para suprimir a identidade (boa e virtuosa) do grupo instaurado no poder. Salvaguardar a própria identidade, sob a máscara da defesa do 
Estado - antes do status quo - é o passo dado pela estratégia da organização da força bruta.

Ao nosso ver, o que Donoso indevidamente releva é que a força bruta para tanto utilizada, juntamente com o iminente risco e insegurança, lança a pedra fundamental de uma nova estrutura de Estado, ditatorial, na qual tudo quanto era alvo de preocupação e tutela termina por definitivamente fenecer. Em conexão com tal aproximação, Cisneros agudamente adverte que é, no momento em que a política começa a ser percebida como guerra, momento no qual a pluralidade e a diversidade são reputadas como indesejáveis em face de uma percepção de mundo excludente, então, "Los regímenes democráticos se establecen y consolidan como una alternativa concreta a la masacre recíproca" (CISNEROS, 2002, p. 632). A tese de fundo que defendemos, portanto, é que a situação de exceção requer mais política, e não menos, mais abertura ao diálogo, e não o alargamento do enfrentamento.

A posição de Donoso Cortés converge com esta à medida que aposta que a garantia do status quo (e da ordem que lhe é inerente) de uma sociedade dispõe de maior valor não exatamente do que os direitos individuais, mas do que os indivíduos em si mesmos. Assim, são justificados os esforços (violentos sempre que necessários) para resguardar tal ordenamento, em descuido completo do que a defesa dos direitos individuais aconselhe (ver DONOSO CORTÉS, 1933a, p. 176). A crítica de fundo é de que Donoso atribui a um único poder, centralizado na figura do soberano, o critério decisório sobre o que precisamente colocaria uma sociedade em risco e que, unicamente, ele está em posição de avaliar qual a intensidade e duração da aplicação do remédio para suplantar tal situação. Com isso, facilmente, passamos de uma situação de proteção da vida em sociedade para uma violação perene de seus interesses mais pela estrutura política ditatorial implementada. Neste aspecto, resta claro que o decisionismo donosiano sobrevive no século XX no texto schmittiano, dado que a sua versão da ultima ratio da ordem política reside no político antes que em um sistema normativo ( $c$. CISNEROS, 2002, p. 626), no máximo, a uma interpretação antinormativa da própria 
Constituição (cf. MÁRQUEZ, 2003, p. 24).

Contra a sociedade, contra os seus fundamentos históricos e os seus valores não poderiam ser brandidos ligeiramente qualquer conjunto de direitos individuais. Neste sentido, De Maistre adiantava o argumento em sua crítica à Revolução Francesa afirmando não existirem direitos escritos assim como tampouco qualquer Constituição (cf. DE MAISTRE, 1990, p. 61), ao menos não da forma como fora pensada até então e que pudesse cumprir as finalidades assecuratórias (e limitadoras) de direitos nela(s) propostas. Assim, De Maistre concluiria que "[...] las leyes fundamentales escritas no son nunca más que títulos declaratorios de derechos anteriores, de los cuales no se puede decir otra cosa, sino que existen porque existen" (DE MAISTRE, 1990, p. 6162). Assim, qualquer ato jurídico presente, ou mesmo fundador, nada mais seria do que uma atualização do anteriormente posto, a saber, que não seria um ato jurídico constitutivo mas, antes, meramente declaratório, um puro reconhecimento do já existente e, sobretudo, um ato político.

Sobre este tema, De Maistre mostra-se relativamente despreocupado. Não elege como prioridade a busca de qualquer fundamento para este direito que passa a ser reconhecido por meio do ato de mero poder a partir de seu reconhecimento de que, naturalmente, que ali sempre esteve criado por Deus um determinado direito que cabe à autoridade temporal reconhecê-lo. Em Donoso essas ideias reverberaram intensamente, de modo a permitir-lhe dar um passo além ao fundamentar a legitimidade do político, e também do direito produzido em seu âmbito, na teologia do catolicismo.

Fundando o direito nos sólidos alicerces da teologia e orientado por movimento idêntico ao realizado por De Maistre, Donoso calça o argumento contra o exercício da resistência política popular e então, objetivamente, sustenta que o povo não se queixaria de que poderes ditatoriais fossem estabelecidos para fins de neutralizar a situação de exceção, pois "El pueblo no se queja, no puede quejarse de una dictadura que le salva [...]" (DONOSO CORTÉS, 1946a, p. 633). Aqui, a ditadura é compreen- 
dida como uma benévola intervenção do poder temporal total, pois ela intervém e provoca resultados análogos ao do milagre em matéria teológica, pois, como bem recorda Márquez, a figura divina do catolicismo a tudo controla ( $c f$. MÁRQUEZ, 2003, p. 24). ${ }^{11}$ Pavani percebe uma dimensão da teologia em Donoso aberta à recepção da ditadura, a saber, quando a compreende como um "[...] instrumento político que reflete a ordem divina ("o milagre"), isso quer dizer que o próprio Deus a utiliza" (PAVANI, 2010, p. 117). É especificamente neste ponto que Pavani admite dizer que o catolicismo de Donoso serve à sua defesa do autoritarismo ( $c f$. PAVANI, 2010, p. 117) e, diríamos, também a outras interpretações tortuosas do teológico.

Nisto Donoso segue faz as linhas de De Maistre sobre o direito, pois nem sequer o povo poderia queixar-se dele por força de que ele é fruto de outorga de um benevolente do soberano ( $c f$. DE MAISTRE, 1990, p. 62). Esta relação de submissão radical entre o povo e o soberano é um pressuposto assumido por Donoso, e então não apenas coloca a ditadura na posição de uma legítima alternativa para o exercício do poder como, passo seguinte, a reputa como um bom ou até mesmo excelente governo, reconhecidas as circunstâncias que se apresentem para o seu emprego ( $c f$. DONOSO CORTÉS, 1933b, p. 166).

1 A leitura de Márquez aponta no sentido de que o "[...] discurso sobre la dictadura, Donoso Cortés sostiene que el Creador gobierna constitucionalmente y "algunas veces directa, clara y explícitamente manifiesta su voluntad soberana quebrantando esas leyes que Él mismo se impuso y torciendo el curso natural de las cosas. Y bien, señores - concluye dirigiéndose a las Cortes -, cuando obra así, ¿no podría decirse, si el lenguaje humano pudiera aplicarse a las cosas [...]" (MÁRQUEZ, 2003, p. 24). Trata-se de um trecho relevante em Donoso à medida que aponta claramente tanto o poder divino de interromper o curso da história humana, ainda que quebrando as suas próprias leis. Por outro lado, esta é a demonstração cabal de sua absoluta soberania, a qual emulará o soberano temporal em seu enfrentamento das situações excepcionais, rompendo, também ele, as normas jurídicas por ele postas e que apenas em sua vontade encontram a sua validade última. 
Esta relação entre soberano e súdito não é reputada por Donoso como o oposto da valoração à liberdade, senão entende que nela o homem pode ser, paralelamente, submisso. Assim, submissão e liberdade não são um oxímoro mas, isto sim, denotam o que seja um cristão perfeito, e é precisamente isso que lhe permite ser livre tanto na presença submissa a Deus quanto aos césares ( $c f$. DONOSO CORTÉS, 1946b, p. 941). Portanto, a submissão política, ainda quando potencializada, não interromperia o virtuoso ciclo da liberdade, senão que, em verdade, ao maximizar tal submissão, dar-se-ia a ampliação e também a proteção daqueles que seriam os seus genuínos detratores, os ilustrados e racionalistas.

Conectada a esta matéria, apresenta-se uma das preocupações de Donoso, qual seja, a de questionar se o povo estaria interessado em examinar a qual título se encontra o governante dotado e exercendo tão expressivos poderes (ver DONOSO CORTÉS, 1946a, p. 633). Segundo um exame abrangente de seu texto, é inviável dar crédito à hipótese de que nutra alguma séria preocupação com a legitimidade do ditador soberano que esteja além das fronteiras observadas pelo campo teológico. O povo encontra-se habituado a prestar obediência e a sua virtude católica apenas consolida-se e aprofundo o hábito, destacando-se tal virtude à medida que permaneça adstrito a esses limites de submissão ao análogo modelo de poder temporal.

Essa teorização do político também é expressa por Donoso por meio de sua resposta político-jurídica ao momento, algo que ganhou espaço em sua LEE. Embora seja certo reconhecer a originalidade do texto, a centralidade dos argumentos ali desenvolvidos encontrava-se já em sua sexta lição das LDP, pronunciada a 10 de janeiro de 1837. Nas LEE, destaca-se a ideia de que, para os períodos revolucionários, a onipotência é necessária ( $c f$. DONOSO CORTÉS, 1946c, p. 275), pois é nesse momento que a Constituição e todas as demais instituições soçobram, posto que não dispõe de força suficiente para enfrentar o conjunto de forças que desestabilizam a sociedade e radicalmente ameaçam a sua existência. 
A pergunta óbvia é sobre quem (e sob quais critérios) haveria de reunir o colossal poder para realizar a tarefa de aprisionar o monstro ( $c f$. DONOSO CORTÉS, 1946c, p. 275). Donoso não demonstra preocupação em responder a isso. Intenso, o poder deveria servir à reorganização do Estado, e a força para cumprir tal tarefa apenas poderia encontrar-se em uma figura onipotente exercício de um poder temporal desempenho por um homem cuja singular fortaleza não pode ser adiantada pelas previsões constitucionais ( $c f$. DONOSO CORTÉS, 1946c, p. 275), e nem tampouco o seu perfil por quaisquer outros meios, exceto a adesão ao catolicismo.

Donoso aposta em que a tarefa Hercúlea de reconduzir o Estado à normalidade é realizável apenas por homens excepcionais, e que precisamente nisto encontra-se o desenho de uma figura à imagem em descrição da divindade, quais ações assemelham-se às do Leviatã, que ruge, e que com isso faz o circo calar-se e o conjunto das tempestades serenar ( $c$. DONOSO CORTÉS, 1946c, p. 276). O político não é tarefa humana, mas transcendente; tão árdua e Hercúlea tarefa não pode encontrar o seu realizador entre os mortais, exceto quando inspirado pela divindade. Assim, o político para Donoso concentra um poder que em absoluto "[...] pertenece al dominio de las leyes escritas, no pertenece al domínio de las teorías filosóficas; es una protesta contra aquellas leyes y contra estas teorias". (DONOSO CORTÉS, 1946c, p. 276).

O poder constituinte não seria apenas uma dura oposição ao mundo, mas sim apresenta-se conectado a uma terrível exceção que condena o gênero humano ( $c$. DONOSO CORTÉS, 1946c, p. 276) e que, por isso, não deve ser formulada racionalmente. Isso sim, tal exceção deve ser entregue à onipotência de Deus em seu inderrotável poder de intervenção no mundo temporal ou, por outro lado, àqueles que intervêm no mundo a justo título para salvar as sociedades em momentos de crise. Portanto, para Donoso, poderes ditatoriais são legítimos e, para avaliar o quão adequados são, nada mais é necessário do que examinar sob a guia de um critério pragmático-utilitário. Esse critério recomenda considerar o êxito no empreendimento político em questão, 
pois é " [...] solo la victoria [que] confiere en esos casos el derecho y legitima el poder" (DONOSO CORTÉS, 1946c, p. 276). Sendo esse um poder tão extenso, resta examinar em que termos o conceito de soberania em Donoso se interrelaciona com a sua noção de obrigações e direitos, tanto dos soberanos governantes quanto de seus súditos e o papel exercido pela crítica liberal.

\section{O discurso da ditadura: a inabordabilidade da excepcio- nalidade pela legislação e a presentificação do teológico como elemento de consolidação do poder}

O discurso de Donoso Cortés sobre a ditadura foi pronunciado no Congresso espanhol a 4 de janeiro de 1849 e, logo, tornou-se célebre. A partir dele operaram os comentaristas para ampliar o raio de compreensão sobre o tema. A importância do objeto é perceptível ainda no século XX e, principalmente por sua releitura por Carl Schmitt e pela sua revalorização na Espanha por um amplo e variado círculo de seus leitores conservadores, ${ }^{12}$ muito embora também em outros países europeus como a Alemanha. ${ }^{13}$

O discurso sobre a justificativa da ditadura por Donoso Cortés foi sucedido por um argumento jurídico recorrente na filosofia analítica contemporânea. ${ }^{14}$ Ainda que de forma incipiente e insuficientemente articulada, Donoso justifica sua argumentação na detecção de lacunas e brechas legislativas, quer devido a impossibilidade de precisa antecipação dos eventos futuros, quer por

12 A recepção de Donoso também ocorre na América Latina, dentre as quais menciono a ocorrida no Chile, sendo um dos grandes leitores do autor Gonzalo Larrios Mengotti.

13 A este respeito cabe anotar o cuidadoso trabalho de aproximação à obra de Donoso realizada por Maschke. Ver MASCHKE, (2007).

14 Especialmente a partir da tradição na matéria consolidada por Hart. O autor ocupa-se sofisticadamente do tema no capítulo VII de seu $O$ conceito do direito (ver HART, 2007). De qualquer modo, não se trata de absoluta inovação do autor, senão que outras fontes anteriores da filosofia analítica (como Austin) mas sobretudo da linguística, já haviam apontado para a questão.

Ano $13 \cdot$ n. $1 \cdot$ jan./jun. $2013-79$ 
força da limitação semântica da linguagem. Estes são referenciais teóricos que Donoso utiliza ainda que algo toscamente para, momento seguinte, alcançar o seu objeto de direto interesse, a saber, a justificação da ditadura em face dos momentos excepcionais.

Em seu DSD, Donoso Cortés traça um importante paralelo entre o mundo físico e o mundo transcendental, segundo o qual Deus é quem governa absolutamente todo o Universo, mas que não o faz diretamente, senão por meio de delegação aos homens e, por conseguinte, o governo de suas sociedades. Smolensky reforça esta aproximação ao comentar que "From this point of view, the prince is not truly the constituent power, because God is the creator of order, including political and legal order. The monarch enforces this order in the name of God" (SMOLENSKY, 2012 , p. 271). Smolensky ressalta a oposição do poder temporal infraposto ao poder transcendente. Trata-se de que o poder é uma derivação do teológico e que encontra seus referenciais tanto em Bodin quanto em Maquiavel, ainda que não exclusiva e excludentemente neles.

No período pré-moderno, essa era uma descrição fidedigna do estado de coisas, enquanto que, na modernidade, é apenas parcial. A Potestas constituens é puro atributo da divindade, e o poder temporal haverá de encontrar-se ao seu dispor quando objetive predisposto a desfrutar de legitimidade (ver SMOLENSKY, 2012, p. 271). Assim, o poder do ditador soberano encontra condições para a sua possível legitimidade também nesta ancoragem na Potestas constituens. O fenômeno da secularização que o século XVIII observou incrementar-se terminou por deslocar este poder de suas origens transcendentes, determinando a assunção da soberania pelo poder temporal, em especial, na leitura revolucionária francesa, no povo, valendo-se da mediação para o seu exercício contra isto, desde logo, articulou-se Donoso.

Mas se é mesmo a divindade quem cria a integridade das normas que regem o mundo físico, então a divindade também pode, desde o alto de sua soberania, segundo seu exclusivo juízo de oportunidade para intervir, rompendo as regras por ela postas (cf. DONOSO CORTÉS, 1904b, p. 114). Aqui reside a ideia de 
Donoso que permite a analogia entre o funcionamento do poder transcendental e o poder político, a concepção humana da hierarquia e força do poder transcendente e o exercício do poder político temporal. Finalmente, resulta que ambos são capazes de transgredir as normas em vigor, postas, em qualquer caso, pelas suas próprias instâncias soberanas. Neste mesmo sentido, evidenciando preocupação com as relações estabelecidas entre essas duas ordens de poder citadas, aponta De Maistre que o milagre é um efeito produzido por uma causa sobre-humana, a qual contradiz uma causa ordinária ( $c f$. DE MAISTRE, 1990, p. 4), e ela interrompe a ordem dos fatos com uma força irresistível, e a essa semelhança é que age o poder temporal por meio da decisão soberana e da ditadura.

Por esse ângulo analítico, observa-se a convergência das noções de legislação e divindade que permeiam o texto de Donoso e que o faz admitir que em nenhum momento o homem pode caminhar sem Deus, tanto quanto tampouco pode abster-se de trilhar na história sem dispor do direito ( $c f$. DONOSO CORTÉS, 1946a, p. 633). Essa é vinculação que aproxima o teológico do político pela via do jurídico, na qual, por certo, não persiste, sequer, nos termos do jusnaturalismo. ${ }^{15}$ A elaboração de um conceito de poder que seja capaz de instituir e manter o direito é vista por Donoso como indefectivelmente ligada à ideia do poder, uno, indivisível e perpétuo, e, assim, o autor reitera o mesmo modelo de intenso poder em ambos os níveis, tanto teológico quanto político.

Essas características formam um conjunto atribuído ao monarca Donoso que, logo, pode ser espelhado, não sem as devidas atualizações, na figura do ditador. Nunca fora dessa circunstância seria possível o firme enfrentamento das situações de

Tendo em vista a marca do catolicismo em sua obra, Donoso poderia ter recorrido, por exemplo, ao jusnaturalismo de Santo Tomás de Aquino para combater as leis injustas que não são classificáveis como direito. Poderia ter buscado inspiração nesta fonte para opor-se aos abusos e vilipêndios gerais do ditador, soberano, mas não o faz. 
excepcionalidade que inspiram a sua LEE. Neste texto, Donoso é bastante claro acerca de a representação não desempenhar papel importante, porém, ainda mais, distancia-se em absoluto da noção de democracia legítima, posto que a compreende genuína em uma matriz centralizadora das decisões na população. A opção de Donoso é pela radicalização da centralização de tal poder já não por meio das instituições monárquicas, que encontraram o seu ocaso em meados do século XIX, mas por intermédio de seus úteis resquícios.

Dentre os resquícios monárquicos, Donoso localiza a herança centralizadora e a cultura pública da submissão a um poder onipotente, ambos absolutamente aproveitáveis pela tradição autoritária. $\mathrm{O}$ caso é que, enquanto isto, outra e bastante distinta, é a marca de uma democracia cuja legitimidade "[...] derives its power from the depth of the political existence of the people [...]" (SMOLENSKY, 2012, p. 271). Por outro lado, para Donoso, o poder soberano jamais poderia encontrar-se calçado neste referencial político conceitual popular, senão nas instâncias superiores, segundo uma visão aristocrática de domínio das virtudes.

Sendo o caso de que Donoso não manifeste qualquer otimismo quanto às virtudes populares, senão todo o contrário - e isto é o que fácil e diretamente se lê em seu trabalho -, não seriam precisamente os momentos de crise que lhe inspirariam para recorrer a esta fonte de poder de tão escassas virtudes. Desse modo, por suposto, não apenas a preocupação como também a solução que aportou ao problema da exceção é representativa de um movimento absolutamente contrário ao conceito mantido pelos liberais e socialistas sobre o núcleo da soberania. ${ }^{16}$ Os liberais, inversamente aos socialistas, detém-se em uma abordagem do conceito de soberania desde uma perspectiva da multiplicidade e da fragmentação, a saber, no povo, e neste sentido, por de-

\footnotetext{
16 É um detalhe importante mencionar que uma série de conceitos com os quais Donoso opera tem como referencial teórico o período e a cultura filosófica e política antecedente à primeira metade do século XIX.
} 
finição, o catolicismo era uma força que apenas poderia antepor-lhes conceitualmente, pois, no texto de Donoso, era manifesto o alto grau de hierarquização e concentração de poderes,${ }^{17}$ um traço político que apenas duramente pode ser compatibilizado com a pluralidade. ${ }^{18}$

Sob tal ordem teórica, Donoso percebe que a monarquia também contribuíra com as suas características de unidade e perpetuidade, inerentes à sua constituição política. São características em absoluto contrárias à fragmentação do exercício do poder por seu titular, o povo. O movimento de Donoso Cortés somente é contrário e radicalizador, ideia para a qual contribuíra De Maistre em seu momento ao caracterizar a Revolução Francesa como um movimento marcado por uma absoluta tirania plebeia ( $c f$. DE MAISTRE, 1990, p. 112). Nesse sentido bem aponta Kalyvas que a reflexão de Schmitt sobre a democracia de massas moderna começa precisamente por meio da análise das consequências derivadas da " $[\ldots]$ postmedieval transition from the sovereignty of the king to the sovereignty of the people, from the unitary, physical body of the monarch to the fragmented, dispersed body of the multitude" (KALYVAS, 2009, p. 88). É claramente perceptível a proximidade entre esta interpretação de Schmitt realizada por Kalyvas e a cultura política contrarrevolucionária presente tanto em De Maistre quanto em Donoso Cortés, intensamente oposta ao processo de fragmentação do poder soberano em prol do triunfo da sua fragmentação nas mãos do povo.

Não há espaço o suficiente para explorar esta ideia, mas o fato é que, historicamente, comprova-se que tanto o liberalismo quanto o socialismo abriram espaços, e muito mais frequentemente esse último, a estruturas de poder e de governo com graus superlativos de concentração de poder e intensas formas de exercê-lo. Assim, o temor donosiano em face da fragmentação do poder que a atribuição da soberania ao povo poderia supor acabou por revelar-se não tão realista, pois, notadamente no caso socialista, a soberania popular não veio a apresentar-se como uma variante empírica do programa político do socialismo real.

18 Há comentaristas que, como é o caso de Franco de Sá, apontam em sentido contrário. Ver FRANCO DE SÁ, (2007; 2003).

Ano $13 \cdot$ n. $1 \cdot$ jan./jun. $2013-83$ 
O absolutismo, portanto, não acompanharia necessariamente a ditadura mas, isto sim, Donoso outorga a essa última a posição de antípoda do racionalismo democrático, e para ilustrá-lo ali estaria o exemplo histórico francês do século XVIII. Sendo estas as características do momento e o tipo de poder que supõe necessário para enfrentar os desafios, logo Donoso ocupou-se de outra ordem de temas. Precisava fazer frente aos problemas a serem enfrentados para a elaboração de uma legislação específica destinada às situações de excepcionalidade. A reflexão de Donoso está ancorada em dois pontos principais, a saber, (a) a indeterminação do direito e $(b)$ a inviabilidade de estabelecer a priori os poderes, os quais, ao menos no caso espanhol, seriam atribuídos aos militares para debelar as ameaças, dadas as reconhecidas limitações teóricas oferecidas pelo âmbito normativo.

\section{3. $O$ argumento da insuficiência técnica do direito}

Embora concebida de modo superficial por Donoso e, de certo, também de modo pouco sofisticado, a ideia da insuficiência técnica do direito é uma questão pouco explorada mas que demonstra preocupação com uma ideia em si mesma altamente relevante para o conjunto da argumentação donosiana. Fundamentalmente do que se trata é que Donoso reconhece a incompletude do ordenamento jurídico e as sérias limitações que isso causa ao pré-estabelecimento jurídico de limitações ao poder excepcional.

Conectado com esta temática técnico-jurídica, Donoso reconhece que o projeto de lei do Governo espanhol sobre a matéria de expansão dos poderes do Executivo continha dois importantes elementos, a saber, (a) que o poder ditatorial cessaria quando deixassem de existir as razões excepcionais que haviam ensejado a emersão de tal poder. A legislação proposta impregnada pela vagueza tanto no aspecto do conteúdo das normas materiais quanto em suas normas adjetivas perpassa e finalmente impede uma precisa determinação dos poderes ditatoriais. Esta ideia era compatível com a plena indeterminação das circunstâncias que poderiam ensejar a outorga de tais poderes. Por outro lado, 
ainda elemento igualmente relevante é que (b) também é vaga a designação das autoridades (aspecto legal formal) que possuem a competência para declarar o estado de exceção ( $c f$. DONOSO CORTÉS, 1946a, p. 638). Esse, contudo, não é um conjunto de circunstâncias legais que provoque maior atenção e crítica normativa de Donoso senão no âmbito descritivo.

Dentro do âmbito da vagueza normativa, Donoso deixa sem qualquer resposta a (a) quem deveria este soberano ditador e (b) quais requisitos haveria de preencher para ser jungido a tal posto bem como $(c)$ a quem deveria ele prestar contas. Em suma, Donoso não prevê qualquer poder capaz de deter o soberano ditador e, com isto, caracteriza-se uma filosofia que abre as portas para a ditadura e permite ampliar-lhe indefinidamente os seus limites. Daí que encontremos plenamente justificadas e em alto nível de congruência interna as investidas de Donoso contra a legislação, mais especificamente enquanto entendida como direito fruto do trabalho político-parlamentar.

Segundo essa ordem argumentativa, o autor é congruente com os seus princípios ao admitir que aos militares será necessário outorgar poderes que a legislação não prevê (e nem pode prever) expressamente ( $c f$. DONOSO CORTÉS, 1946a, p. 633), pois esta será a única possibilidade de instrumentalizar o poder que alegadamente apenas visa à reorganização da situação de excepcionalidade e a reconstituição do status quo ante. Nesse sentido há quem sustente que o Discurso sobre la dictadura, em último termo, apoiava-se argumentativamente na constatação da insuficiência das medidas legais das quais dispunha o poder em sua elaboração teórica do direito (cf. BARTYZEL, 2011, p. 145).

Neste texto sobre a ditadura, Donoso argumenta que é possível justificá-la. Preocupa-se em sublinhar que há certas circunstâncias sob as quais isso poderia ocorrer, e que sob elas dar-se-iam todas as condições para que ela fosse considerada um governo de tipo absolutamente legítimo ( $c f$. DONOSO CORTÉS, 1904b, p. 112). Ainda mais que, sob a égide destas circunstâncias extraordinárias, a ditadura seria mesmo adjetivável como um bom governo e, ademais, como proveitoso e defensável como qualquer 
outro tipo de governo tão virtuoso como seja possível imaginar, quer do ponto de vista teórico quer do ângulo prático ( $c f$. DONOSO CORTÉS, 1904b, p. 112). Embora o próprio Donoso não a ponha em vistoso destaque, uma primeira leitura mais cuidadosa e ampliada desse trecho faz emergir uma condicionante para que a ditadura possa ser bem considerada, a saber, que existam certas circunstâncias que, logo, serão identificadas como de excepcionalidade. Contudo, em um segundo olhar analítico, o que resta evidente é que Donoso não indica minimamente a delimitação dessas circunstâncias, e pensa o tema de forma ampla o suficiente para que a instauração permanente da ditadura seja uma fácil opção pelos detentores do poder. Dada a ampla gama de poderes outorgada ao ditador, uma vez instaurado, tal regime ditatorial é dificilmente interrompido, quer por instrumentos jurídicos ${ }^{19} \mathrm{ou}$ ainda por mecanismos políticos, que, em nosso autor também, já aparecem neutralizados pela força do poder.

Donoso menciona que as medidas fortes adotadas em face das circunstâncias de excepcionalidade aportam decisiva e favoravelmente para vencer o radical enfrentamento das situações de graves desordens internas, de revoluções armadas, e este é um conjunto de circunstâncias que, desde as considerações da técnica jurídica, encontram-se elididas da possibilidade de pré-determinação dos poderes nem, por conseguinte, a pré-ordenação de seus limites. Assim, o que existiria na concepção de Donoso seria uma limitação técnico-jurídica, e não exatamente política, interpretação que não apoiamos posto que, se o direito não pode antecipar todas as situações e nem mesmo toda a amplitude de poderes para enfrentar o inaudito, é também certo que há muitas técnicas jurídicas disponíveis para cercar eventos futuros de sorte a tornar o absolutamente imprevisível subsumível em uma formatação legal presente em que o temor ao autoritarismo possa ser controlado

19 Em Donoso os instrumentos jurídicos de controle do poder político aparecem por completo indisponíveis ao conjunto da população, pois estão desarticulados desde dentro e controlados pelo soberano.

86 - Universidade Católica de Pernambuco 
segundo níveis de mínimo risco. Essa não é, desde logo, a preocupação evidente no texto de Donoso.

Decididamente, um grande problema presente nesta interpretação do texto de Donoso com a qual divergimos é de que abre considerável espaço não apenas para a instalação da ditadura, mas que o faz de modo definitivo. Quando não põe em questão um cuidadoso debate sobre as limitações às quais deveria estar exposta e os mecanismos de controle, o que finalmente o autor demonstra ser a sua aposta é uma ditadura como regra, não como exceção. Em suma, o que lhe falta a Donoso para que a sua concepção de ditadura pudesse ser entendida como instrumento excepcional são recursos significativos, a saber, dedicados minimamente ao cuidado com $(a)$ bem limitar o regime ditatorial em suas ações; (b) estabelecer claros mecanismos protetores contra eventuais abusos em seu legal exercício segundo controle político; (c) claros instrumentos de ordem normativa para que a ditadura seja mantida adstrita a um determinado lapso temporal; ${ }^{20}(d)$ que com a restauração do status quo ante, subsistam ainda instrumentos institucionais fortes e intensos o suficiente para vergar os vestígios da cultura político-jurídica da ditadura e, por conseguinte, desarticulando-a internamente, propiciar os meios para que encontre o seu ocaso.

O cenário com o qual dialoga Donoso é que o convence acerca da necessidade de preparar uma resposta imediata para o enfrentamento das situações de graves desordens internas, revoluções ou, passo adiante, de agressões armadas externas. No cenário histórico espanhol, estava em célere construção o teatro de

20 A crítica com a qual esta limitação se depara e que, supostamente, tornaria inabordável o próprio objeto que leva à instauração da ditadura, posto que o êxito de seu empreendimento político não pode ser determinado a priori. Mas se isto é realmente certo, instrumentos há, tais como o da renovação de poderes (por parte de um legislativo independente) que pode servir como mecanismo restritivo. Desde logo, essa é uma ideia que pode ser atacada por quem trabalhe com um conceito absoluto de soberania. Nosso propósito foge ao objeto de debater o quão desejável é um regime marcado por um poder político deste tipo, de caráter concentrado e extremado. 
conflitos radicais. $\mathrm{O}$ autor sugere que as províncias espanholas poderiam ser submetidas ao jugo de uma ditadura com o escopo de garantir a primazia do poder central, prévio movimento visando a reverter o quadro de ameaças à estabilidade, e para tanto reservar-se-ia às autoridades militares a faculdade de, quando reputassem necessário, transgredir o dever de guardar respeito às leis. Nesse sentido, portanto, consideramos equivocada a posição que relega apenas a um segundo plano a ideia de que Donoso amplia implicitamente os limites legitimadores do conceito de ditadura para muito mais além da gravidade que o enfrentamento armado supõe, pois esta é uma noção decisiva para pensar a ditadura e a teleologia ínsita nas linhas de quem a conceba.

Retomando o problema mencionado alguns parágrafos acima, a saber, de ordem técnico-jurídico e também o elemento linguístico que lhe permeia, mas agora conjugando aos problemas de instabilidades sociopolíticas, é que Donoso dá vazão à ideia de que a legislação haveria de ter uma composição consideravelmente flexível, a saber, atribuindo aos militares uma ampla faculdade discricionária para que de suas ações derivassem os resultados esperados, tanto por intermédio de suas ações políticas como ao lançar mão de meios e estratégias duras para os enfrentamentos (cf. DONOSO CORTÉS, 1946a, p. 634). Donoso reconhece que o projeto de lei proposto pelo governo espanhol para enfrentar as circunstâncias e a dupla ordem de problemas mencionados logo acima continha duas importantes vertentes, a saber, (a) que o seu conteúdo deveria ser fixo e (b) e, paradoxalmente, ao mesmo tempo vago.

Esta ordenação de princípios prevista no projeto normativo espanhol, à partida, sugere uma invencível contradição. $\mathrm{Na}$ ótica de Donoso, do que se trata, é de que tal concepção normativa propiciaria que a inflexibilidade de conteúdo previsto nas normas jurídicas repercutisse positivamente sobre as necessidades de intervenção prática nas situações de exceção à medida que, no coração das normas inflexíveis, subsistisse um importante raio de indeterminação e vagueza, sendo exatamente esse o espaço em 
que agiria o poder excepcional.

A excepcionalidade poderia estar marcada por um estado de iminência de guerra, ou de "prevención", ${ }^{21}$ no qual o poder estabelecido encontra-se facultado para transcender os limites fixados pela lei ordinária, e este é precisamente o poder concedido aos chefes militares, ou seja, bastante superior. A este respeito diz o autor que "El estado de prevención es aplicable cuando un territorio, sin estar en estado de guerra, está fuera de su estado normal [...]" (DONOSO CORTÉS, 1946a, p. 638). A marca da instabilidade tem seu território demarcado por Donoso de modo mais preciso do que em outros conceitos com os quais trabalha, e, precisamente, refere-se a que esta situação ocorre quando seja o caso de " $[. .$.$] insurrecciones parciales, [...] a causa de una conspi-$ ración, bien por ser limítrofe de territorios o puntos insurreccionados que le amenacen". (DONOSO CORTÉS, 1946a, p. 638). Mas bem, quando a situação transcende os limites do estado de prevenção, então, a outorga de poderes deve ser realizada de forma mais abrangente do que as competências estabelecidas para os tempos ordinários, embora, por sua vez, sejam estas ainda inferiores àquelas de que dispõe Donoso para os tempos de guerra aberta ( $c f$. DONOSO CORTÉS, 1946a, p. 637).

É importante destacar que não apenas no caso de guerra Donoso permite que os militares transpassem os limites já nada estritos de sua concepção da lei. A falta de preocupação é alargada por sua ausência de referência expressa relativamente à intensidade, frequência e as consequências das eventuais transgressões no que tange às liberdades individuais e coletivas. ${ }^{22}$ Neste cenário,

21 No ambiente de enfrentamentos, Donoso também admite a existência de um "estado de prevención", entendido este como um estágio intermediário entre o estado de paz e o estado de guerra aberta (cf. DONOSO CORTÉS, 1946b, p. 637).

22 Embora fuja ao recorte teórico proposto para este artigo, é importante assinalar que a outorga de poderes para ações preventivas em face de supostas ameaças é, também, a justificativa para as agressões preventivas, política externa desenvolvida pelo Governo conservador dos Estados Unidos da América durante a Administração de George Bush. 
desenhado por Donoso, não haverá decisão ordinária do Poder Judiciário com poder para contrapor-se às soberanas ações das autoridades políticas soberanas em seu exercício do poder. Segundo a perspectiva de Donoso, tais movimentos do Poder Judiciário não podem ser capazes de discernir aqueles que serão os instrumentos necessários para enfrentar as ameaças presentes. Isto sim, esta posição é ocupada por um árbitro último sobre a conveniência ou não de aplicar a decisão judicial ou, então, de suspendê-la sine die, ainda que sem propriamente eliminar o Poder Judicial enquanto instituição. Neutralizá-lo desde dentro, restringindo o conteúdo de suas ações e os limites de sua competência em favor do soberano, segundo uma hierarquia em que este ocupa o ápice.

Mas sob certa ótica, poderia parecer razoável que os períodos de guerra e de enfrentamentos militares internos supusessem a outorga de poderes ditatoriais ao governo; por outro lado, a oposição presente nestas linhas à teoria donosiana é que não haja qualquer empenho teórico em cercar com algum cuidado e, por conseguinte, exercer uma tarefa de limitação de sua teoria da ditadura. Ao não delimitar com mínima precisão esta possibilidade ditatorial, o autor termina por abrir espaços para a expansão da ditadura para o puro e cru enfrentamento no plano político, ponto cuja assunção remete a que as autoridades políticas possam transferir as suas ações do plano do mero risco e ameaça para o plano do concreto dano, transformando-se o sistema de um suposto guardião da ordem e do cuidado em restabelecê-la, em um sistema, por definição, transgressor dos valores essenciais do Estado.

A compreensão deste texto é mesmo de que, em Donoso, a ditadura deva mesmo vigorar como regra, e não como mera excepcionalidade, algo que se deve essencialmente a que o seu forte apoio à instauração do regime não elabora um mecanismo de bloqueio para a sua perpetuação. Em outros termos, trata-se de que por trás do discurso donosiano, encontra-se a vaga ideia de dever pesar sobre tal regime alguma forma de regulamentação para fins de emprestar-lhe certa legitimidade, mas não há, desde logo, em momento algum, uma preocupação com a clara e posi- 
tiva limitação desse poder, uma vez instaurado, e os mecanismos de proteção pública contra ações abusivas em seu exercício.

Excluindo-se a possibilidade da ingenuidade teórica, o fato concreto é que Donoso não hesita em afirmar que se uma ditadura encontra-se autorizada pela lei, ou seja, que ela " $[$...] exige la más estrecha responsabilidad a los mismos a quienes confiere la más terrible dictadura" (DONOSO CORTÉS, 1946a, p. 634). Esta é uma leitura cujo primeiro olhar remete a uma interpretação inversa àquela proposta nestas linhas. Contudo, é sabido que Donoso é um dos mais ácidos críticos do Parlamento e seria um absoluto contrassenso atribuir a ele a competência para a criação de normas jurídica capazes de limitar precisamente aos poderes ditatoriais, menos ainda no caso das mais terríveis ditaduras, conforme menciona Donoso.

\section{Considerações finais}

A ampliação da compreensão não apenas da gênese como da teleologia da teoria da ditadura de Donoso bem como também de sua assunção da violência como instrumento de realização do político não pode ser em absoluto deslocada de sua grave crítica ao parlamentarismo e da noção de autoridade com a qual trabalha o autor. É sua a máxima, que logo seria recuperada por Schmitt, que classifica os membros do Parlamento como uma classe de discutidores, indecisos homens, partícipes de um processo visceralmente falido. Contudo, assim como também viria a argumentar Schmitt, o parlamentarismo era uma instituição que, uma vez bem constituída, encontraria os melhores instrumentos para opor-se a governos transgressores de suas atribuições legais. O problema fulcral era que esta virtude parlamentar fora perdida no curso da história e ficou isolada de suas valorosas origens britânicas e que, contemporaneamente, já não havia mais espaço para ela em sua forma atual irreversivelmente atingida.

O que faz Donoso é apostar na ampliação de poderes dos governantes. O que Donoso observa é bem mais do que o problema da crise parlamentar, mas sim a necessidade da emergência 
de um novo regime que disponha de instrumental para controlar os tempos de crise. Para isso não estaria apta a cultura política liberal e de seu parlamentarismo democrático. Assim, sob o pretexto logicamente sustentável e politicamente razoável de que as situações concretas de crise transpõem a possibilidade de previsibilidade do legislador, Donoso logo conclui, como vimos, que a opção política a ser seguida é a ampla atribuição de poderes ao Poder Executivo.

Isto é certo, o Marquês de Valdegamas desconsidera que há preços provavelmente políticos tão altos a ser pagos pelas opções que tomemos, que bem podem apresentar-se como absolutamente insustentáveis, definitivamente divorciados de qualquer noção de razoabilidade, sempre e quando tenhamos por parâmetro que há honestidade nos declarados propósitos de proceder à defesa das liberdades cidadãs vigentes em um determinado ordenamento jurídico que também se queira manter.

Das linhas deste texto acreditamos restar clara possibilidade de uma interpretação de que, para Donoso, há um único mundo virtuoso cujos valores merecem a pena ser defendidos, porém, ainda mais, que é a favor dele que devemos empregar legitimamente todos os nossos melhores e mais decididos esforços, ainda mesmo quando a divindade não garanta o triunfo final nesta empreitada. Isso aponta para que entre a manutenção do status quo e a vontade política de caráter emancipador que indique o caminho da ruptura não haveremos de titubear, e ao decidir-se pelo primeiro, o autor também justifica o emprego de meios repressivos contra os insurgentes, sejam eles identificados ou não com a população, e com o emprego das mais terríveis forças de que possa dispor uma ditadura para lograr o seu desiderato.

Este texto trabalhou com duas referências de base, autoridade e política, com o escopo de aproximar ao conceito de ditadura em Donoso, indica que tal conceito foi sendo gestado ainda bem antes de seu célebre Discurso sobre la dictadura, texto normalmente trabalhado como eixo para discutir a ditadura. Conforme visto, nossa perspectiva é de que há muitos outros elementos que sustentam que a visão da ditadura exposta por Donoso em 
seu Discurso sobre la dictadura lança raízes profundas em outros textos que o antecedem. ${ }^{23}$ Um deles é a sua Ley de los Estados Excepcionales, publicada na Revista de Madrid no ano de 1839, no qual Donoso torna clara a convergência do teor ácido de sua crítica à política liberal com a incapacidade do Parlamento para gerir as crises políticas e, passo seguinte, sob tal pressuposto teórico, abrir espaço para a consolidação de sua visão sobre o valor da ditadura.

A utilização conjunta de uma via hermenêutica que reúne a perspectiva (a) histórica, $(b)$ material de suas fontes (de Maistre) e (c) abrangente de outros textos do próprio autor, finalmente permitiu a construção de um marco teórico mais sólido que aponta para a leitura de um autor que mostra o seu compromisso não com uma ditadura para tempos excepcionais mas, isto sim, que toma a esta como a porta de entrada para uma outra ditadura, como regra.

\section{Referências}

BARTYZEL, Jacek. Tres encarnaciones de Donoso Cortés: constitucionalista - decisionista - providencialista. Fundación Elías de Tejada. Annales XIX, Anuario del Centro de la UNED, Barbastro. 2011. Disponível em: http://www.fundacioneliasdetejada.org/Documentacion/Anales/ PDF\%20ANALES\%2016/ANA16-P-139-146.pdf Acessado em: 6 de janeiro de 2013.

CISNEROS, Isidro H. Génesis de la política absoluta. Estudios Socio-

23 Como foi possível observar ao longo deste trabalho, centralmente os textos considerados foram a Ley de los Estados Excepcionales (DONOSO CORTÉS, 1946a). Este texto encontra-se integralmente disponível na internet, ver http://cdigital. dgb.uanl.mx/la/1080014261 C/1080014263 T3/1080014263 75.pdf. As suas Lecciones de Derecho Político (DONOSO CORTÉS, 1946c) foram tornadas públicas ainda antes de sua LEE, pois foi curso ministrado no Ateneo madrilenho entre os anos de 1837 e 1838 . Outra obra igualmente considerada aqui e que também antecede ao nuclear discurso sobre a ditadura é La civilización de España (DONOSO CORTÉS, 1946b). 
lógicos. No. XX, vol. 60, 2002, p. 625-639.

DE BONI, Luis Alberto. (Org.). Escritos Seletos de Martinho Lutero, Tomas Muntzer e João Calvino. $1^{\mathrm{a}}$. ed. Petrópolis: Vozes, 2000. 275p.

DE MAISTRE, Joseph. Consideraciones sobre Francia. Madrid: Tecnos, 1990.

DONOSO CORTÉS, Juan. Discurso sobre la dictadura. 4 de Enero de 1849. In: DONOSO CORTÉS, Juan. Textos Políticos. Madrid: Ediciones Rialp, 1954, p. 451-482.

. Ley de Estados Excepcionales. In: DONOSO CORTÉS, Juan. Obras Completas de Donoso Cortés. Tomo I. Madrid: Biblioteca de Autores Cristianos, 1946a, p. 627-640.

. La civilización de España. In: DONOSO CORTÉS, Juan. Obras Completas de Donoso Cortés. Tomo I. Madrid: Biblioteca de Autores Cristianos, 1946b, p. 931-946.

. Lecciones de Derecho Político. In: DONOSO CORTÉS, Juan. Obras Completas de Donoso Cortés. Tomo I. Madrid: Biblioteca de Autores Cristianos, 1946c, p. 211-331.

. Carta al Director de El Heraldo. París, 15 de abril de 1852. In: DONOSO CORTÉS, Juan. Obras escogidas de D. Juan Donoso Cortés. Madrid: Apostolado de la Prensa, S.A., 1933a, p. 173-177.

. Discurso sobre la situación de España. In: DONOSO CORTÉS, Juan. Obras escogidas de D. Juan Donoso Cortés. Madrid: Apostolado de la Prensa, S.A., 1933b, p. 147-170.

. Discurso sobre la situación general de Europa. Pronunciado en el Congreso el 30 de Enero de 1850, al discutirse el proyecto de autorización al Gobierno para plantear los presupuestos de aquel año. In: DONOSO CORTÉS, Juan. Obras de Don Juan Donoso Cortés. Dirección y Prólogo de Don Juan Manuel Orti y Lara. Vol. II. Madrid: Casa Editorial de San Francisco de Sales, 1904a, p. 159-182.

. Discurso sobre la dictadura. In: DONOSO CORTÉS, Juan. Obras de Don Juan Donoso Cortés. Dirección y Prólogo de Don Juan Manuel Orti y Lara. Vol. II. Madrid: Casa Editorial de San Francisco de Sales, 1904b, p. 109-132.

FRANCO DE SÁ, Alexandre. Decisão, crença e o sentido da ordem concreta no pensamento de Carl Schmitt. LusoSofia Press. Universidade da Beira Interior. Covilhã. 2007. P. 3-19. Disponível em: www. 94 - Universidade Católica de Pernambuco 
lusosofia.net/.../sa alexandre franco de decisao_e crenca.doc.pdf Acesso em: 21.Abril.2011

. Sobre a justificação racional do poder absoluto: racionalismo e decisionismo na Teologia Política de Carl Schmitt. Revista Filosófica de Coimbra. No. 23, 2003, p. 157-180.

GÓMEZ ORFANEL, Germán. Normalidad y excepción en la historia constitucional. s/d., p. 1-21. http://www.acoes.es/congresoX/documentos/ComMesa4GermanGomez.pdf

GONZÁLEZ CASANOVA, José Antonio. La cuestión de la soberanía en la historia del constitucionalismo español. Disponível em: http:// www.unioviedo.es/constitucional/fundamentos/primero/pdf/gcasano.pdf Acessado em: 19 de dezembro de 2012.

HART, Herbert. O Conceito de Direito. $5^{\mathrm{a}}$. ed. Lisboa: Fundação Calouste Gulbenkian, 2007. 348p.

HOPFL, Harro. (Org.). Coleção Clássicos Cambridge de Filosofia Política. In: CALVINO, João; LUTERO, Martinho. Sobre a autoridade secular. In: $1^{\mathrm{a}}$. ed. São Paulo: WMF Martins Fontes, 2005. 151p.

KALYVAS, Andreas. Democracy and the Politics of the Extraordinary. Max Weber, Carl Schmitt, and Hannah Arendt. Cambridge: Cambridge University Press, 2009. 326p.

LUTERO, Martinho. Da liberdade do cristão. 1 $^{\text {a }}$ ed. Campinas: Unesp, 1998. 127p.

MÁRQUEZ, Jesús Silva-Herzog. Carl Schmitt. Jurisprudencia para la ilegalidad. Revista de Derecho. (Valdivia). Vol. XIV, Julio, 2003, p. 9-24.

MASCHKE, Gunter. Introdução. In: CORTÉS, Donoso. Essay über den Katholizismus, den Liberalismus und den Sozialismus: und andere Schriften aus den Jahren 1851 bis 1853. 3a. ed. Vienna: Karolinger Verlag, 2007. 576p.

PAVANI, Roney Marcos. Repensando o conservadorismo católico: política, religião e história em Juan Donoso Cortés. Dissertação de Mestrado em História Social das Relações Políticas. Recuperado en: http:// 
www.ufes.br/ppghis/Documentos/2008/Roney\%20Marcos\%20Pavani20Turma\%202008\%20DEFESA.pdf

SÁNCHEZ GARCÍA, Raquel. Reflexiones sobre la Revolución en torno a 1848. Ayeres en discusión [Recurso electrónico]: temas clave de Historia Contemporánea hoy. MARÍN, María Encarna Nicolás; MARTÍNEZ, Carmen González. (Org.). 2008. Disponível em: http://www.ahistcon.org/ docs $/$ murcia/contenido/pdf/05/raquel_sanchez_garcia taller05.pdf Acessado em: 10 de janeiro de 2013.

SCHMITT, Carl. Die geistesgeschichtliche Lage des heutigen Parlamentarismus. Berlin: Duncker \& Humblot, 2010.

. La unidad del mundo. Conferencia pronunciada en la Universidad de Murcia. In: Escritos de Política Mundial. Buenos Aires: Editorial Heracles, 1995. P. 135-146.

SMOLENSKY, Jan. Substantive equality, popular sovereignty, and antagonistic politics: an introduction to Carl Schmitt's democratic theory. CEU Political Science Journal. Vol. 7, (3), 2012, p. 269-289.

SPEKTOROWSKI, Alberto. De Maistre, Donoso Cortés, and the Legacy of Catholic Authoritarianism. Journal of the History of Ideas. Vol. 63, No. 2, April, 2002, p. 283-302. 